\title{
A Systematic Analysis for the Business Model of Warner Brother
}

\author{
Catherine Chen ${ }^{1, *},{ }^{*}$ Randy Gan ${ }^{2, *}, \dagger$ Xinyan $\mathrm{Wan}^{3},{ }^{*}, \dagger$ \\ ${ }^{1}$ Carlmont High School Belmont, California 94002, US \\ ${ }^{2}$ Los Gatos High School, Los Gatos, California 95032, US \\ ${ }^{3}$ Teensen Genesis School, Nanchang 330038, China \\ *Corresponding author.Email: ${ }^{*}$ guanghua.ren@gecacdemy.cn; ${ }^{b}$ cc2004live@live.com; ${ }^{c} 1750789051 @ q q . c o m$ \\ These authors contributed equally.
}

\begin{abstract}
The world of entertainment is an ever-changing minefield. With so many factors that influence the entertainment industry, it is always shifting and changing. What might be the current situation could be rendered obsolete only a few years down the line. To stay afloat in this fast-paced environment, companies must adapt and overcome changes as soon as they appear. As such, the industry is extremely competitive, with companies large and small all grappling for the attention and money of a diverse consumer base. Companies like Disney, Netflix, Hulu, and Tik Tok all thrive off of the interest of their users. In this paper, we will address Warner Brothers Inc. and evaluate its abilities to succeed in the entertainment industry and analyze Warner's potential to survive in the future.
\end{abstract}

Keywords: entertainment, industry, diverse consumer.

\section{INTRODUCTION}

Warner Brothers is one of the largest film companies in the media industry. Warner has an impressive total market cap of greater than $\$ 73.4$ billion, making it one of the six biggest American film studios. Over the last two years, its average sales totaled $\$ 32$ billion annually in 2019 and 2020. Warner has seen incredible success over the years by producing films beloved by both American and international audiences. Such names include the Harry Potter movies and the entirety of DC Comics movies. Warner Brothers' current business strategy is to release about 20-25 movies per year, including 3-5 bigbudget "event" movies. [1] However, as the entertainment industry changes, companies must adapt and change to continue growth and development.

GURL [2] has researched the SWOT analysis and its qualitative and descriptive nature. The study examined the SWOT analysis in historical, theoretical, and time frame perspectives as an effective situation analysis technique that plays an important role in the fields of marketing, public relations, advertising, and any others requiring strategic planning. The SWOT analysis is a method used to evaluate the 'strengths', 'weaknesses', 'opportunities', and 'threats' involved in an organization, a plan, a project, a person, or a business activity.
Doug Leigh [3], a psychology professor at Pepperdine University, has also conducted similar research on the intention and usage of the SWOT analysis. $\mathrm{He}$ has found that it is primarily used to identify internal strengths and external opportunities that an organization can leverage to accomplish its objectives while also seeking to mitigate internal weaknesses and external threats.

Nigel Piercy [4], a consultant and independent researcher, found that the analysis of Strengths and Weaknesses and Opportunities and Threats are the most common and widely recognized tool for conducting a strategic marketing audit. Although useful at first glance, the authors suggest the SWOT analysis has suffered from familiarity breeding contempt and that the technique is normally used very badly and to little effect. The article draws on experiences from marketing planning process management in various companies to propose a fivepoint approach to make SWOT analysis work more effectively.

After much research, we found that, despite Warner already being one of the largest companies in the entertainment industry, there are still tremendous opportunities that have yet to be unlocked. As shifts in the entertainment industry happen, companies must adapt 
to accompany the changes in their market. We believe that Warner has all the right physical tools and intangibles to allow them to adapt to new trends more successfully and efficiently than others in the same industry. In this paper, we will first give insight into the firm's past and current market strategy. This will provide background information about who Warner is as a company and what they strive to achieve. Next, we will conduct a SWOT analysis of Warner Brothers. Understanding Warner's strengths and opportunities will shed light on what Warner should focus on to succeed in the future. In addition, by analyzing the threats and weaknesses posed against Warner, we can determine the course of action Warner must take to avoid failures in their industry. Following the SWOT analysis, we will also analyze the effects of Porter's Five Forces which include threats of new entrants, bargaining power of suppliers, bargaining power of consumers, the threat of substitutes, and overall competition in their field. Finally, we will provide ample reasoning for the future success of Warner and recommendations for actions Warner should take to become even more dominant in the entertainment industry.

\section{FIRM DESCRIPTION}

Warner Brothers Pictures is a film and television company under Time Warner. This enterprise integrates the creation, production, distribution, and dissemination of various forms of audio and video and related products. It was founded in 1985 by Stephen Jay Ross. Some of its many products include but are not limited to films, television programs, DVD production, cartoons, comic books, music, games, and so on. Some of the most defining movies that secured them great success in the past include the Harry Potter series, the Hobbit movies, Inception, and all DC movies.

According to Lawrence [5], currently, with the COVID-19 pandemic keeping cinemas closed, Hollywood giant Warner Bros. recently announced its plan to release all 2021 films simultaneously in theaters and on its subsidiary streaming service HBO Max, disrupting a long-held film release and distribution model. This is a big example of how Warner has adapted to current trends and how much of the entertainment industry is moving closer and closer towards online subscription services. Warner has made a monumental decision that could send shockwaves throughout the entertainment industry. While other companies in the past have also followed the subscription service business model, few of them have the same amount of brand recognition, and overall significance as Warner Bros. Warner has access to a plethora of different franchises, with notable characters like Batman, Spider Man, Bugs Bunny, Harry Potter, and others. With their strengths, Warner certainly has the potential to grow HBO Max into a colossus in both the world of subscription services and the entertainment world.

As of 2021, Warner Brothers is a subsidiary of AT\&T and is one of the largest entertainment companies out there. With a market cap of more than $\$ 73.4$ billion, it is one of the six biggest American film studios and has around 26,000 employees. Its average sales total \$32 billion annually over the last 2 years $(2019,2020)$, but there is still room to grow. With all this being said, we believe that there is firm evidence to support the reasoning that Warner Brothers could continue to grow, perhaps even surpassing names that have been staples of the entertainment industry in the past, such as Netflix and Disney. 


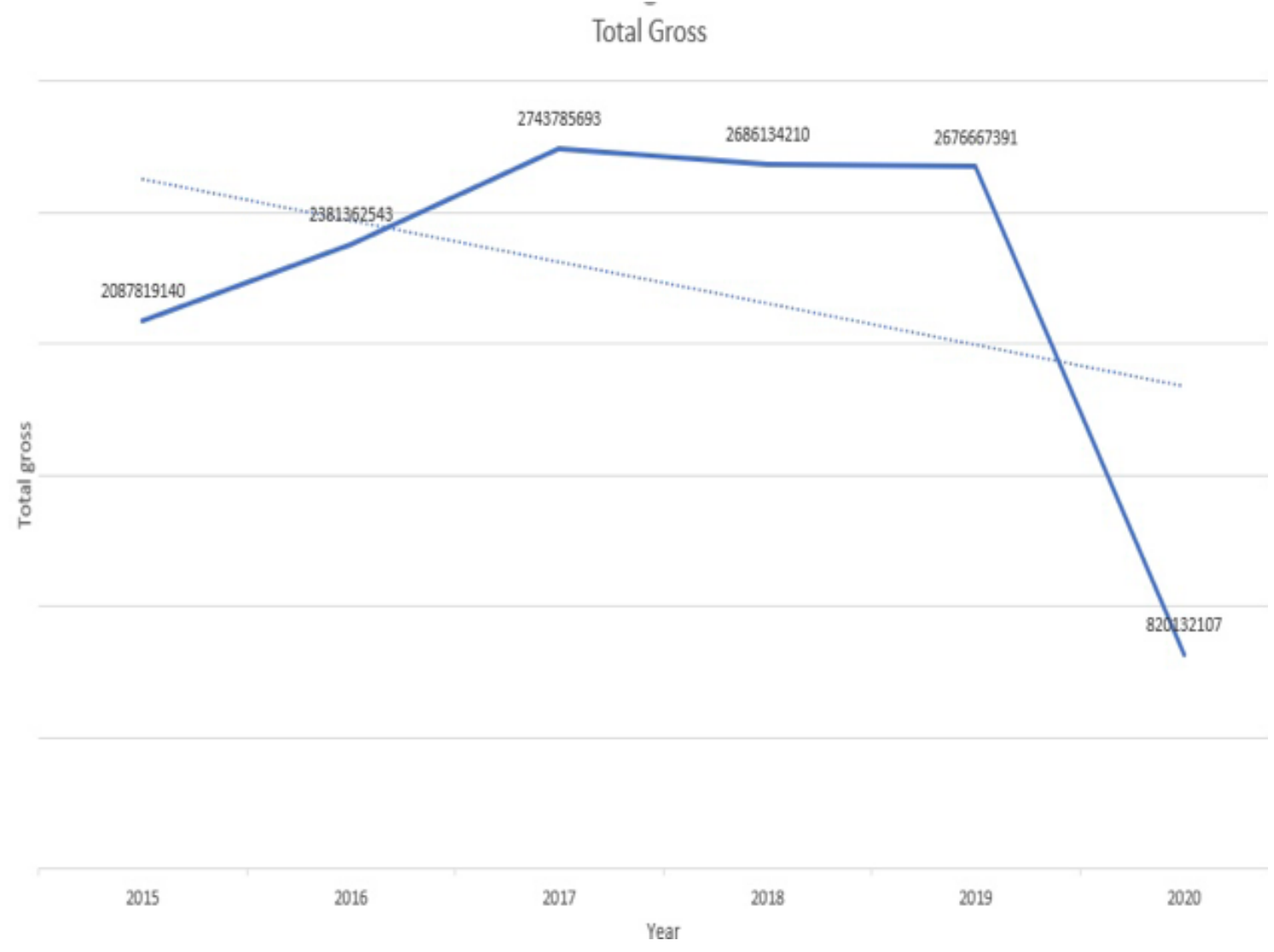

Figure 1. gross per year for this company

The figure above is a line graph describing the total gross per year from 2015 to 2020 . As shown in this graph, in the three years spanning from 2015 to 2017, the gross estimate reached a peak of 2.7 billion. From 2017 to 2019, the total gross revenue remained at a similar level. However, the situation bottomed out at 0.8 billion due to the influence of the global COVID-19 pandemic.

\section{SWOT ANALYSIS}

The SWOT analysis is a common strategic planning instrument that highlights an organization's strengths, weaknesses, opportunities, and threats related to business competition or project planning. Using SWOT, we can identify a company's unique value proposition and determine how it may perform in the future, given its strengths and weaknesses. SWOT also allows us to find a company's niche in their target demographic through analyzing their opportunities. Conversely, SWOT may also give insight on what an organization must do to stay relevant by analyzing threats that may pertain to their field. Overall, SWOT is a useful tool to understand the complex structure of organizations.

\subsection{Strengths}

To begin with Warner's strengths, it should be noted that as one of the world's largest entertainment companies, Warner Brothers has a world-renowned brand making it easily identifiable and recognizable. As such, the company is also a long-withstanding stronghold financially and continues to expand. With the company's rich assets comes an equally rich knowledge of movie production and firsthand experience of how the industry works, owing to its long history.

Being such a large company has its advantages, including being one of the few movie studios that have the right to produce and distribute their own movies. Another benefit is that human resources are abundant, including the best of the best directors, screenwriters, actors, and an experienced and flexible staff team of more than 8,000 people. Being a critically acclaimed media company, it has produced some of the biggest and most decorated Hollywood blockbusters, including the entire Harry Potter series, the entire Hobbit trilogy, and various DC Comics movies like the many Batman movies.

As Warner Brothers is actually a subsidiary of Warner Media, there are several other smaller branches under its parent company that it can work with, such as Time Inc., Warner Brothers Entertainment, and New Line Cinema, each a distinctive company in their own right. In this way, more information and resources are available to Warner Brothers, helping it grow faster than its competitors. Collaborative projects with other famed enterprises in the same or different industries are also a strategy and resource for the company, such as cooperating with HP to develop special effects for 
movies or with video game manufacturer Blizzard to develop movie-related games. A particularly profitable venture is the agreement with Netflix Inc. that allows consumers to stream various Warner Brothers' movies on the platform.

\subsection{Weaknesses}

Although being a large company has its highs, it also has its considerable lows. Being such a famous company means constantly being watched by the industry and consumers to see what the next step you make is. More pressure is put onto the company to uphold a pristine public image, and their actions have that much more weight in the public's eyes. If even one small misstep is made, the media tends to blow the issue extremely out of proportion into highly publicized mistakes, casting a shadow on and staining the company's reputation. This can be seen with following the market or pop culture trends. As companies have to constantly reinvent themselves to be up to date with society and capture the public's attention, following such trends is a must and should be reflected in their products and services. However, some trends can be misinterpreted or insensitive. If a company still follows it, consumers will boycott its products, leading to a downward spiral that is often extremely hard to get out of for companies, considering how fragile but crucial public relations is for business.

Among other issues, scandals, bribery, corporate espionage, disguised monopolies, and corruption of highranking officials are just a few examples of problems that could majorly upset a company's stability and bring it to ruin. The movie production industry is already highly volatile due to its inherent content being constantly influenced by the whims of the media and the public, and to add to that, the success of movies is never guaranteed, even with a strong team backing it. Consequently, the many other business ventures surrounding the content from those movies, such as theme parks and physical merchandise, are also affected. Even a movie that appears to be successful at first may turn sour later down the line due to various factors. One well-known example of this is the J.K. Rowling incident in which many fans started boycotting or getting rid of their Harry Potter merchandise due to her making not one but many discriminatory insults towards transgender people. This financial instability is often offset by attempting to diversify asset allocation. Still, there is no denying the fact that the success of movies, whether at the box office or digitally, is the path to commercial profit.

\subsection{Opportunities}

Warner Brothers have not entirely tapped into the potential of HBO Max. As more and more of the entertainment industry shifts to online streaming services that allow users to stream content from the comfort of their own homes, many entertainment companies struggle to adapt to this trend. Netflix, Hulu, Disney Plus, and others are some examples of streaming services in the entertainment industry that are very well received and often used by consumers. However, HBO Max, while having potential, is yet to be placed on the same level as other streaming services. If Warner Bros were to invest more time and resources into further developing $\mathrm{HBO}$ Max by adding more TV shows, movies, and other forms of content, they would be able to captivate a larger audience of users that commonly use online entertainment services while also raising company image and profits in the process.

Taylor [6], an economics professor at Duke, has explored the practice of enticing subscribers to switch suppliers in his studies. This type of competition is natural in subscription markets for homogeneous goods and services. It is shown that efficiency is impaired because subscribers are induced to expend more capitalchanging suppliers than staying loyal to their current ones. Subscription markets are fully competitive only when three or more firms serve the industry. In this case, the price offered to switchers is below the cost expended, while non-switchers pay a larger premium. Each firm earns rent on its customer base but has zero expected profit on each new subscriber it attracts. Meaning for a subscription service to be successful, it needs to build a large follower base that will use it month after month, rather than cancel or switch every month or so.

This notable feature of subscription services begs the question, will Warner's HBO Max be considered service users would be willing to switch to more well-known streamers like Disney Plus or Hulu? We truly believe that while HBO Max is not on the same level ground as elite subscription services like Netflix, it has a solid foundation that Warner can easily build on and grow into perhaps the most popular subscription service. With each, almost all, of Warner's movie releases being big box office drivers, consumers would be more willing to pay a subscription fee if it meant that they could get early access to upcoming DC movies or Harry Potter spin-offs. With all this being said, if Warner continues to develop HBO Max properly and add to their iconic collection of movies, HBO Max could potentially grow to become the face of subscription services as a whole.

An added bonus would be that if Warner Brothers were able to completely outdo themselves and bring a revolutionary detail to their digital streaming services, then they would also cement themselves as one of the leaders in the industry for technological advancement and movie experience enhancement. Introducing new installments to its successful franchises such as sequels or spin-off series is also something Warner Brothers has yet to tap into the potential of. Two options can be taken with adding more films to franchises: to see if the original 
authors and creators have any content they are willing to adapt into more films. Another is to obtain licensing for the characters and other original material to create a new sequel themselves. The Lord of the Rings, Batman, and Harry Potter are such franchises that are popular enough to warrant more content.

\subsection{Opportunities}

While Warner Brothers have been successful in the past, there are threats present to its dominance. The first being the decline of the DVD, which was inevitable considering the advances in modern technology. DVDs are becoming more and more obsolete as of the current age. Now, with cloud sharing capabilities and subscription streaming services hosting a wide array of entertainment options without the need for a clunky DVD file, there is almost no need for DVDs in the film industry. After all, not many people would purchase a Blu-ray disc for up to ten times the cost for a month of access to Netflix. Moreover, increased piracy is another massive threat that could pose disastrous for Warner Brothers in conjunction with the decline of DVDs. Piracy has been a long-time issue but recently has gained traction due to how ubiquitous it has become. Piracy sites have become much more present, whether being able to be found throughout the web with ease or by word of mouth from friends and family. With such widespread piracy, much of the need to spend hard-earned money for entertainment has disappeared, as the same product on legal sites can be found for free with the help of piracy, just a simple click away. After all, why take the long, hard road when there's a shortcut?

Smith [7], a professor of Information Technology and Marketing at Carnegie Mellon University, has found that this issue has recently gained renewed importance with the advent of high-definition digital television. Movie studios argue that unless copy protection is included in digital television standards, it will no longer be profitable for them to show movies through unprotected airings of films on broadcast channels. Their concern is that digital transmission standards and personal video recorders will allow consumers and pirates to make perfect digital copies of movie broadcasts, resulting in increased piracy and reduced demand for DVDs and movie outings.

The largest and most prominent threat that Warner Brothers faces is the increase in the popularity of subscription services. With so many other entertainment companies following the subscription service business plan, no company wants to fall behind, especially given the profitable success that follows most streaming services. Failure to adjust to the changing landscape will most likely spell commercial disaster for those reluctant to hop on the subscription service bandwagon. Warner has a subscription-based service named HBO Max, but as previously stated, it has not been as fully developed as other subscription services. If HBO Max ends up flopping, it would be a massive failure for Warner, considering the time and resources they have poured into it. Warner must develop HBO Max to the best of its ability to remain a dominant force in the media industry.

\section{Porter's Five Forces AnAlysis}

Porter's Five Forces is a method for analyzing the competition that a business faces. It considers the threat of new entrants, bargaining power of both suppliers and consumers, threat of substitute products, and overall competition in the same field. By dissecting these five elements, we can explore the competition a company faces from different perspectives and evaluate the probability of success in the future.

\subsection{Threat of new entrants}

The threat of new entrants is very low in the case of Warner Bros Inc. It is very unlikely that they will be affected by any new entrances in the field of entertainment because they have been around for so long. With time comes brand reliability and market dominance, both of which Warner Bros has cultivated in great amounts. They have many loyal customers who will continue to buy into forms of entertainment created by Warner Bros, even if new suppliers emerge. In addition, it is also incredibly difficult for any new entertainment company to make serious ground against Warner Brothers, let alone any other large entertainment company. This is because the associated costs to compete with companies like Warner, Disney, or Marvel are too high for small start-up companies to afford. The money that goes into casting the big-name actors, renting or buying film equipment, and applying special effects is simply too much.

\subsection{Bargaining power of suppliers}

The bargaining power of suppliers in regards to Warner is relatively low. There is not an abundance of large film industries, so suppliers will have to turn to Warner one way or another. Suppliers of Warner provide filming equipment, a very niche market. As stated before, there aren't too many large film companies that can challenge Warner's size and brand reliability (perhaps only a handful of five or six). With this knowledge, it is reasonable to conclude that it is in suppliers' best interest to continue business relations with Warner.

\subsection{Bargaining power of consumers}

The bargaining power of consumers is very high in the entertainment industry. With so many different companies, apps, and games all fighting tooth and nail for the time and attention of consumers, Warner will have to compete with film companies and threats from beyond the film industry. Consumers can easily choose to watch 
a Marvel movie over a DC movie or perhaps choose to occupy themselves with social media rather than Warner's movies and games. There are no switching costs associated with changing from Warner to some other form of entertainment outside of the media industry. To be successful, Warner will have to capture consumers' attention in a way that makes them difficult to be ignored. Luckily, Warner is already marching towards that goal with the development of HBO Max and their commitment to broadening the appeal of their movies.

\subsection{Threat of substitute products}

Silver and McDonnell [10] have studiously examined the movie theater industry in the U.S. McDonnell, a Professor of Hydrology at the University of Saskatchewan, and Silver, a specialist in film, screen, and animation at the Queensland University of Technology concluded that movie theaters in the U.S. might have recently reached the end of a period of crisis. However, they argue that the major problems are not over for the industry. After the COVID-19 pandemic, most movie theaters in the digital era have adopted a remarkably similar strategy, which is albeit very vulnerable to recent trends such as the explosion of home cinema, pay-TV, Video on Demand (VOD), discounting of DVDs, video games and the collapse of traditional broadcasting windows on TV.

With the current decline of movie theaters, more and more alternate forms of entertainment are available to users. Some big examples of substitutes include social media, video games, or TV shows; it all depends on what consumers feel like spending their time and money on at the moment. Warner needs to make their service or product appeal to the masses even more than other more convenient forms of entertainment, most notably being Tik Tok with its one-minute limit on content. While the threat of substitution is high in the entertainment industry, the profits are immense. If Warner can find a way to circumvent the decline of movie theaters while retaining their current audience, they will find considerable success.

\subsection{Competition}

As Warner holds a much-coveted seat at the top of the entertainment industry, they directly compete with other large media firms such as Disney, Columbia Pictures Inc., and Marvel Studios, producing blockbuster films. Smaller companies like Touchstone and Miramar, which focus on producing low-cost films, are also competitors, but much less so due to the sheer level of brand recognition of Warner Brothers. Finally, they also indirectly compete with other forms of entertainment such as social media, television, and video games to control consumers' attention.
Mass distribution of entertainment content tends to be done through cable and satellite television, as this is the oldest and most common form of dissemination for television and films. Aliloupour [8] Of all the cable and satellite television companies, Bloomberg reports industry leaders and their market shares in the cable and satellite industry, indicating that there are ten major firms in the North America sector comprised of the following companies: Comcast, Direct TV, Time Warner Cable, DISH Network, Charter Communications, Cablevision Systems, Echo Star, Shaw Communications, BCE Inc., and Rogers Communication. Of these 7 companies, Bloomberg specifies that Comcast has the highest sales, followed by Direct TV, Time Warner Cable, and DISH Network. Comcast has a market share of $26.7 \%$, Direct TV's market share is $20.5 \%$, Time Warner Cable has a share of $14.20 \%$, and DISH's share is $9 \%$. Together, these four companies hold $70.4 \%$ of industry shares, and the six other companies combined have a mere $29.6 \%$.

\section{LIMITATIONS AND IMPLICATIONS}

While the upside of Warner is massive, there are certain limitations of Warner that may hinder its success. One such roadblock that stands in the way of Warner's success is the current system of subscription streaming services. As previously stated, although HBO Max is among one of the top streaming services, it is still a few steps behind the truly dominant ones such as Disney Plus, Hulu, and Netflix. If Warner fails to develop HBO Max into an elite service that can compete on the same level as those, they will be unable to cast themselves as the ruling media company. Especially with the decline of movie theaters, it is becoming more and more relevant that streaming services are of the utmost quality.

A second hindrance in the way of Warner is piracy. In the past, piracy may have been a low priority for Warner, but piracy is rampant in today's digital environment. If Warner does nothing to protect against the spread of pirated material, especially theirs, then it will constantly eat away at their profits. People are unwilling to spend their hard-earned money on entertainment when they can find the same movie or TV show on a pirated site to watch said media free of charge. A third limitation is that our paper regrettably does not have many graphs, financial reports, or stock information on Warner Brothers because it is a private company. A final limitation is that although small film companies have no chance of competing against Warner financially, they are well aware of this and thus have developed different strategies to promote their films to small, dedicated niches. Many people in these target niches also believe that smaller companies have more time to focus on the quality of their films. In contrast, large firms such as Warner are more profit-driven and focused on pleasing the general public. While these factors may limit the potential success of Warner, we firmly believe that with 
the right course of action, Warner can grow to become the most dominant force in the entertainment of the twenty-first century.

\section{CONClusion}

In our paper, we dissected Warner's strengths and potential and its market through SWOT, Porter's Five Forces, and data analysis. Thus, we believe that Warner has all the needed tools to become the largest name in the entertainment industry.

Through our analysis of Warner Brothers, we identified their strengths, weaknesses, opportunities, and threats, as well as the overall competition Warner faces. We have found that Warner holds an advantage over other film companies because of their rich assets, which have been acquired over time and experience. Additionally, Warner has become one of the largest film companies that have retained the rights to produce and distribute their own movies due to having the assets to do so, owing to their long history. These advantages have put Warner in a position to succeed as there are very few companies that can match both Warner's size and distribution ability. However, even more notable than Warner's current strengths is their potential to dominate the streaming service industry--the untapped potential of HBO Max is at Warner's fingertips. Most of the world has shifted towards online streaming services due to their convenience and accessibility. HBO Max, while ambitious, has not been fully developed. So far, HBO Max contains a few TV shows by Warner and a large selection of movies. However, this is nowhere enough to compete with rivaling streaming services like Disney plus and Netflix. That being said, if Warner were to continue adding new releases of their most popular movies as well as adding new TV shows that might not even be a part of the Warner Brothers label, they have a serious shot at becoming the face of the entertainment industry.

\section{REFERENCES}

[1] Bros, W. (2007). Entertainment. Gotham City Rises: Batman Begins, Disc, 2.

[2] GURL, E. (2017). SWOT analysis: A theoretical review.

[3] Leigh, D. (2009). SWOT analysis. Handbook of Improving Performance in the Workplace: Volumes $1-3,115-140$.

[4] Piercy, N., \& Giles, W. (1989). Making SWOT analysis work. Marketing Intelligence \& Planning.

[5] Lawrence, K. (2021). Warner Bros. Bets on Streaming. SAGE Publications: SAGE Business Cases Originals.
[6] Taylor, C. R. (2003). Supplier surfing: Competition and consumer behavior in subscription markets. RAND Journal of Economics, 223-246.

[7] Smith, M. D., \& Telang, R. (2009). Competing with free: The impact of movie broadcasts on DVD sales and Internet piracy. Mis Quarterly, 321-338.

[8] Aliloupour, N. P. (2016). The Impact of Technology on the Entertainment Distribution Market: The Effects of Netflix and Hulu on Cable Revenue.

[9] Vlados, C. (2019). On a correlative and evolutionary SWOT analysis. Journal of Strategy and Management.

[10] Silver, J., \& McDonnell, J. (2007). Are movie theaters doomed? Do exhibitors see the big picture as theaters lose their competitive advantage? Business Horizons, 50(6), 491-501. 